\title{
Effects of Using Digital Tools on the Process of Memorization
}

\author{
https://doi.org/10.3991/ijet.v16i04.18285
}

\author{
Amine Hamzi, Noureddine Echantoufi, Jalal Khouna ${ }^{(凶)}$, \\ Lotfi Ajana \\ Sidi Mohammed Ben Abdellah University, Fez, Morocco \\ jalal. khouna@usmba.ac.ma
}

\begin{abstract}
Recent studies show that the effect of digital tools has a direct impact on attention, motivation, autonomy and academic success. In Morocco, considering the extent to which students use digital tools, precisely scientific students, and because of the essence of memory to all learning, this article is part of the overall framework of a study that attempts to find the link between the use of digital tools and the process of memorization. The factors that can influence the memorization process are multiple and diverse: biological, psychological, and sociological. These factors are unquantifiable in most cases, where it is difficult to determine with certainty their degree of impact, or to experimentally show the nature of their influence on the memory process that constitutes the most important function of the brain being the most complex organ of the human being. Therefore, in this article, we will only stick to the duration of use of digital tools as an evaluable parameter, and we will try to determine the link between this duration and the memorization process in order to determine the conditions for healthy and efficient usage.
\end{abstract}

Keywords_-Digital tools; Memory; memorization; learning process

\section{Introduction}

By looking at the modern period (1980-present), the world has experienced a real "digital revolution" which was the result of the significant improvements in Internet technologies, such as virtual emails and messaging. The development of technologies took a long time, but finally we ended up with our most used tool today: social networks. Since then, the digital tools have become essential in our daily lives. They have significantly evolved in the recent years. The first generation of computers were inefficient, slow, less responsive and unattractive. Within a short amount of time, the computer has become more and more powerful, responsive, small and thin. It kept evolving until the appearance of its most advanced derivative form; the touch tablet. Thanks to this exponential development, digital tools are now making our life easier, and it is difficult for most of us not to use smartphones or internet. It is almost impossible today to find a house with no smartphones or computers. Therefore, social status does not seem to be a determining factor that can prevent a citizen from owning or 
using a digital device. Now, we literally live in a digital world. Everything is turned digital, including art, books and even national education.

\section{Theoretical Framework}

\subsection{Impact of digital tools}

Due to the significant use of digital devices and their rapid evolution, many scientific researches started to study their impacts on human health and on the human psychology, which appears to be outdated either immediately after the results have appeared or sometimes even before, and that is a constraint for those scientific studies. Scientists in several fields try to better understand digital tools' influence on different sides and from multiple angles of vision on the human being, and to answer major questions related to their impact [1]; [2]; [3], but the results are usually themselves a contradictory subject. Educational decision-makers are doing their best to integrate digital tools into the various teaching and learning activities; on the other hand, the recently published results indicate how the contribution of digital tools to these educational activities is negligible and sometimes negative as they increase the cognitive cost of an activity, which is an obstacle to achieving an educational goal. [4]

Besides, neurologists claim that the frequent use of digital devices leads to the creation of a new neural circuit, and thanks to brain plasticity, we gain the skills that will be used to adapt this digital evolution [5].

Whereas, some say that we must be careful with the notion of brain plasticity because even the brain has limitations. Also, the use of these tools as external memories reduces the strength of our memory, which leads to digital amnesia. Confirming the previous facts, studies have shown that the information provided by a search engine is easily forgotten [6]

For sociologists, there are two stated opinions; First, the ones who see social communication apps as a gift that made sharing knowledge and ideas an easier endeavor. Second, those who consider that the permanent accessibility of the internet and digital devices leads the person to desocialization by spending more time in the virtual world than the real one; she tends to play in an armchair and does not play real sport, texting with relatives and not hosting parties, comment with emoticons instead of speaking out loud. As a result, we face a serious risk of destroying our social relationships rather than enhancing them [7], in the same picture, Francis Eustache says: "The work in cognitive neuroscience shows that one of our brain networks (the default network) which is essential for our psychic balance is activated when we turn to our internal thoughts, which means we abandon ourselves to daydreaming, and to introspection, which is not conducive to the intensive use of metal crutches. Finally, memorizing songs, poems, etc., nurtures sharing and solidarity, strengthens the social bond, and improves the quality of living together." 


\subsection{Models of memory}

As far as memory is concerned, the problem of a general definition arises depending on how the functioning of memory is modelled.

Memory is the means by which we record and withdraw from our experiences the information we need at the current moment [8].

As a process, memory refers to the dynamic mechanisms of information storage and recovery related to experiments [9]

Currently, cognitive psychologists have identified three operations inherent in memory; encoding, storage and retrieval [10].

Thanks to the progress of scientific researches, the structure of memory and the memory process are becoming more and more understandable. As a result, it is indicated that memory is multiple, classified into several subsystems capable of operating autonomously while being interconnected [8]

In fact, the memory corresponds to a series of modular processes that follow one another. First, the selection and acquisition of information. Next, retention or storage of information, and recovery or updating [11]; [12]

Basically, the model exhibited is Atkinson-Shiffrin memory model [11]. From an architectural point, this model is based on three different types of memories; Sensory memory, which they call the Sensory Information Register (RIS), Short-Term Memory (MCT) and Long-Term Memory (MLT). Those two researchers distinguish between the three dissertations based on their information processing, and on the time the information takes to retain. [11]

Sensory memories or sensory information register (ris): It is the neural trace of a sensory perception of which the two main senses are hearing and vision, this memory allows attention. In other words, it is the briefs responsible for the selection and acquisition of information. Sensory memories are ephemeral (duration is less than $1 \mathrm{~s}$ ) if the content is not verbally recoded.

It is the nerve effect of sensory perception in the main senses; hearing and vision so this memory allows an attention. In other words, summaries are responsible for selecting and obtaining information. Sensory memories are ephemeral (duration less than 1 second) when the content is not encoded orally.

For that, there is a visual (iconic), auditory, olfactory, tactile and kinesthetic sensory memory (coding movement).

Short-term memory or work memory: "A system that temporarily maintains and manipulates information while performing tasks, such as comprehension, learning, and reasoning" [13]

According to Baddeley's model of working memory, the short-term memory (which they refer to as working memory), would consist of a central administrator interacting with the phonological loop and the visuo-spatial notebook. [14]

Accordingly, the phonological loop corresponds to an unconscious mechanism responsible for storing verbal information, and the visuo-spatial notebook would instead be responsible for storing visual and spatial information. The final structure of this model is the central administrator, its role would be to monitor and coordinate the processing operations of the other two systems. 
Some scientists tend to bring those two types of memories (short-term memory and work memory) together because of their temporary retention of information, while others like Baddeley and Hitch distinguish between them.

Cowan for example, persists in distinguishing between these two briefs, which he believes are different somehow. [15]

According to him, short-term memory would only have the role of maintaining information, while in working memory information would be maintained for the purpose of being manipulated and transformed. Therefore, it is a dynamic and nonpassive memory [12].

In brief, the main features of the MCT are; short duration (20 to 30 seconds), limited capacity (7-2 pieces of information) and sensitivity to interference [14]. Moreover, it has multiple roles; It temporarily maintains a short series of information to manipulate it (calculation, problem solving, verification, decision, understand it, and mentally repeat or analyze it out loud in order to permanently save it [14]. This capacity allows the information to be deeply encoded and transferred to long-term memory.

Baddeley has added a long-term working memory (episodic buffer) that makes it easy to exchange between the central administrator and the long-term memory, which keeps the essential information available for several minutes in order to compare new information, carrying out an intellectual task or knowledge already stored in longterm memory [10]

Long-term memory: Long-term memory is used to record information from working memory. And, unlike the two previous structures, it is durable and permanent. Besides, the capacity of this memory is undefined; information can be retained for a lifetime. There is a tendency today to say that it is unlimited. [11]

However, it should be noted that while information can be retained very interminably, others are sometimes inaccessible in our memory (temporarily, even permanently). We are talking about the phenomenon of forgetting.

Researchers subdivided this long-term memory into several modules [8]. That means we will differentiate between explicit memory and implicit memory. The last corresponds to everything that cannot be explained with words, such as things that you know how to do but you find difficult to explain (cycling).

Whereas, explicit memory contains information that is certainly remembered and can be simply named and described by words.

Tulving contrasts two types of memory within explicit memory; episodic memory and semantic memory. Episodic memory concerns memories about our lives, it is more of autobiographical memory. On the other hand, Semantic memory stores everything related to knowledge about the self and the world. Briefly, it is the memory of knowledge. [8]

Thus, for information to be permanently stored in our memory, it must go through these three types of memories that work in interaction. [11]

The way an information is then transferred to the long-term memory and how it is recovered depends on a number of parameters in addition to the implementation of facilitating strategies.

These strategies include mental repetition, spread at the time of learning, the psychological and physical context while retrieving information, the number of sensory 
methods involved in capturing information, and the depth of processing. This step makes more free space on the working memory level.

Recovery is essential for memorization because it allows the individual to implement or return what he has acquired. It usually involves three types of mnemonic processes; a recall process, recognition, and relearning conduct.

\section{Research Goals}

In light of these memorization models, our research is a continuation of studies that seek to determine the impact of digital tools on the determinants of limiting effective learning.

It focuses here is on memorization because of its importance in most or all of the learning processes.

The article is part of a comprehensive study on the influence of digital tools on the memorization process. So, this study aims firstly to identify the duration of use that can influence the memorization process and its nature. Secondly, determine the types of memories affected. Finally, determine the conditions for healthy, rewarding and effective use.

We will hypothesize that the influence of digital tools depends primarily on the duration of use.

\section{$4 \quad$ Research Methodology}

\subsection{Research approach}

The angle of approach chosen in this article is cognitive psychology and modular models of memory.

Indeed, many experiments tend to say that information (words, images, sounds) can be stored in different ways in our memory. Time and recording capacity are key factors in distinguishing these different storages. Thus, the information is first stored in sensory memory for a few hundredths of a second, then in short-term memory for a few seconds, and finally in long-term memory permanently.

With this type of model, we realize that we can no longer talk about the memory but memories. from a dynamic perspective, it can also be said that information passes from one memory to another in the manner of communicating vases. However, the transition from one memory to another functions as a bottleneck.

Only a small portion of the information stored in sensory memory goes into shortterm memory and some of the information in short-term memory is stored in longterm memory [13]. This brief presentation of the workings of memory and the plurality of storage modules multiplies the question; on what memories do digital tools work? 
Recent studies in neurology showed that there are permanent changes in the organization of neurons (neuroplasticity) so that the brain can adapt and effectively perform these spots.

From this perspective, the exploratory study takes a quantitative and qualitative approach to describe the use of the digital tools (types of digital tools used, frequency of use, and areas of use) and to know users' perceptions of the impact of digital tools on memory in particular as well as other essential components in learning, namely motivation, attention, intelligence.

\subsection{The target population}

Data collection is based on a paper questionnaire and on an interview with participants. This has facilitated access to a wide range of data of both the qualitative and quantitative type. Quantitative data obtained from a questionnaire obtained from an all-Moroccan sample of 374 scientific students, $71 \%$ of whom are students from the Dher El Mehrez Faculty of Science (FSDM), and 29\% from the Fez Higher Normal School (ENS). The sexes are divided as follows: 173 males; 201 women with an average age of 19.5 years, these data are supplemented by an interview with 72 scientific students who have already answered the questionnaire, $37.5 \%$ male and $62.5 \%$ female.

\subsection{The study tool}

The questions focus on the use of digital tools and their impact on memory (see Appendix). They are developed based on variables such as: frequency, duration, and user areas of use and perceptions of the impact of these digital tools on memory. These variables describe the use nature of the digital tools by scientific students, and analyse the influence of these digital tools on their memories.

Testing the hypothesis of the influence nature of digital tools on memorization depends essentially on the duration of use. A memory test is based on tests that have already been created and have proven their validity and reliability as ("MMS") [17]; (MOCA) [18]; ("Tym") [19] and ("5motsDubois") [20] ; DMS-48) [21]and ("RL/RI 16") [22]. However, due to the specificity of the context, target population, and objective study, the study is based on an original memory test (see Appendix) that lasts 8 minutes, and includes three parts:

Part 1: The participant tries to remember the names of the 25 images within 2 minutes, which are in Arabic language proper (teaching language) and not in Moroccan dialect Arabic (DARIJA) whose aim is to stimulate long-term memory, since all the selected images are known in the primary.

Each answer is just 1 point awarded. In order to integrate the time component, the score obtained for this part will be multiplied by a coefficient equal to 1 if it succeeds to complete it in one minute or by 0.5 if it succeeds to complete it in 2 minutes.

Part 2: The participant tries to remember the 25 images that are previously seen in the first part within 2 minutes without seeing them again, and without any allowed time for memorization. This part involves the visual memory (one of the powerful 
sensory memories) because the participant relies on what he has seen. Taking into account that the participant is not warned before (the first test), but anyway, he will need to remember the images.

Same as part 1, each answer is just 1 point awarded. In order to integrate the time component, the score obtained for this part will be multiplied by a coefficient equal to 1 if it succeeds to complete it in one minute or by 0.5 if it succeeds to complete it in 2 minutes.

Part 3: The participant repeats the 2nd part, but this time by getting 2 minutes to memorize the 25 images and being warned that he will need to remember it.

This part involves short-term memory since the participant consciously tries to memorize the data within a limited time, so this part offers the opportunity to assess the impact of repetition on memory. The evaluation way is similar to those in the $1 \mathrm{st}$ and the 2 nd part.

At the end of the test, the participant would get a score that sums up the 3 parts.

\section{$5 \quad$ Results and Discussion}

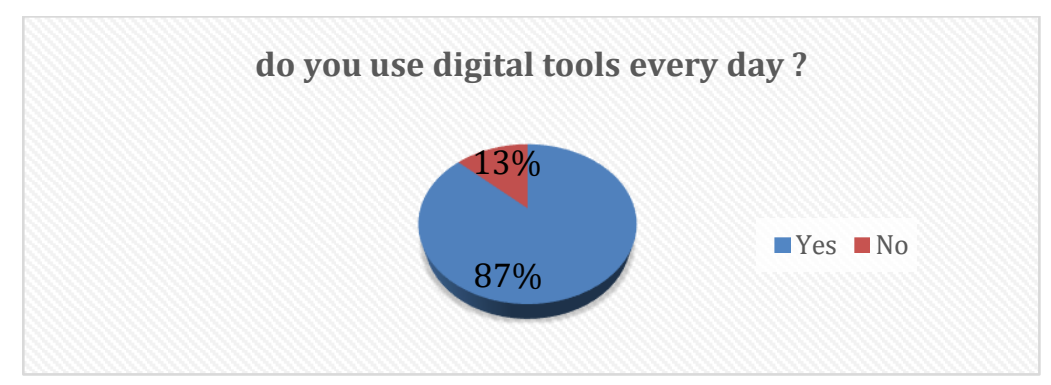

Fig. 1. Frequency of using the digital tools

Based on the result above, students use the digital tools more than ever. Similarly, we can see that they are equipped with at least one smartphone. So, this small device with a large attractive capacity and an increasingly powerful memory offers its user an internet access, where all information is available, it also guarantees a world of entertainment that is difficult to manage and that's why 9 out of 10 people use the digital tools every day. But what is the rate of that use? 


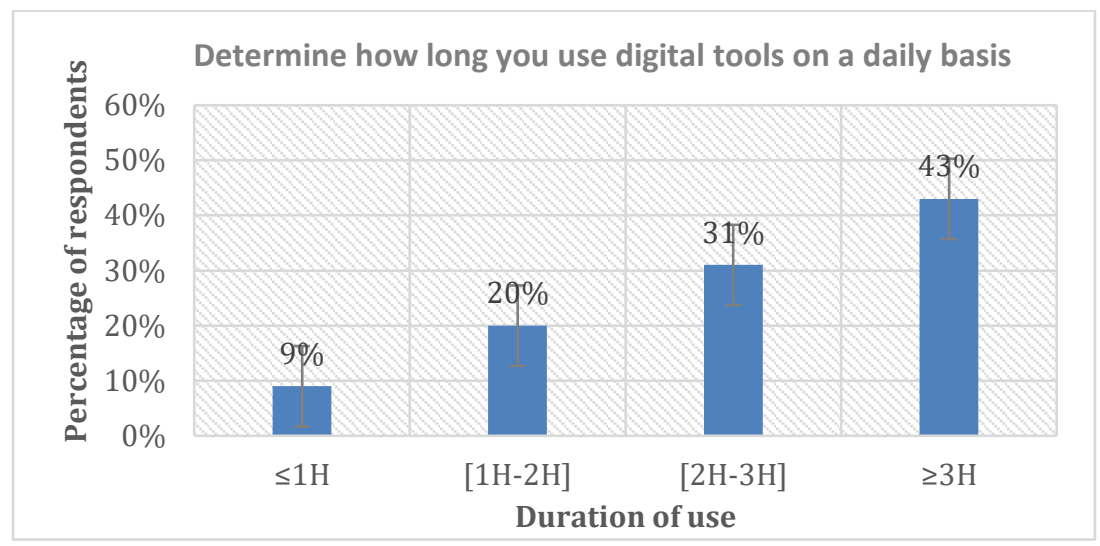

Fig. 2. Daily use of digital tools

Based on the results above, we note that the increase in usage time is accompanied by an increase in the number of users. So, the number of students who spend a considerable amount of time using these digital tools is increasing dramatically.

If we exclude sleep time that lasts an average of 8 hours per day, we find that almost half of students spend $18.75 \%$ of their free time using digital devices which are estimated to 1440 hours per year.

This little calculation shows the frightening extent of this use if it involves unprofitable areas from a personal or professional point of view. In other words, if our students spend 1440 hours/year texting on social networks or watching videos on YouTube, this can't have a positive impact especially on the field of education. But if this big amount of time is diverted to other beneficial areas, it can then be seen as a solution for learning issues.

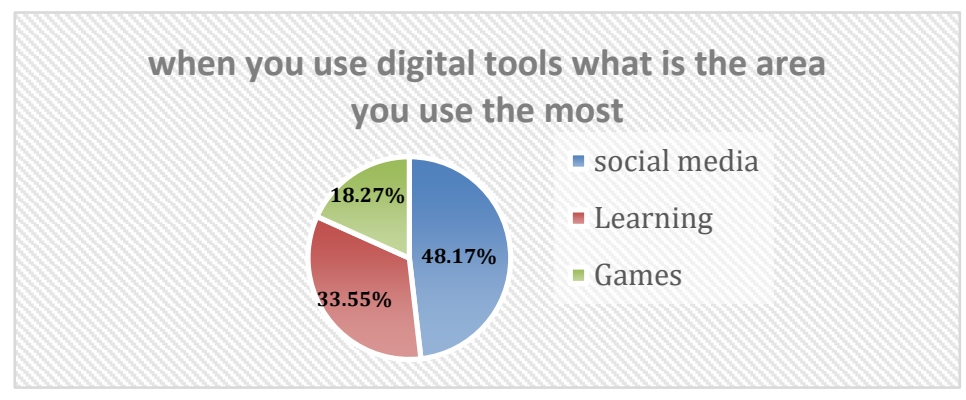

Fig. 3. The most used domain

The results obtained tend to confirm that the use of the digital tools is not adequate, because only $1 / 3$ of the duration of the use is devoted to educational purposes, and the other $2 / 3$ is devoted to so-called entertainment areas namely social networks and games. 
If we put this disturbing result away, the same one can be considered positive because it tells us about the areas where our students want to pass the time, and that is where we need to interact as educational leaders.

Therefore, it is better to adopt new pedagogies than sitting idly, and to study that side of the problem by putting our hands on the alarm bell and not rethinking the old pedagogies, and by looking for methods that better meet the new needs of our students. So, further researches need to answer the major questions, such as, how necessary it is to integrate the digital tools into our pedagogies?

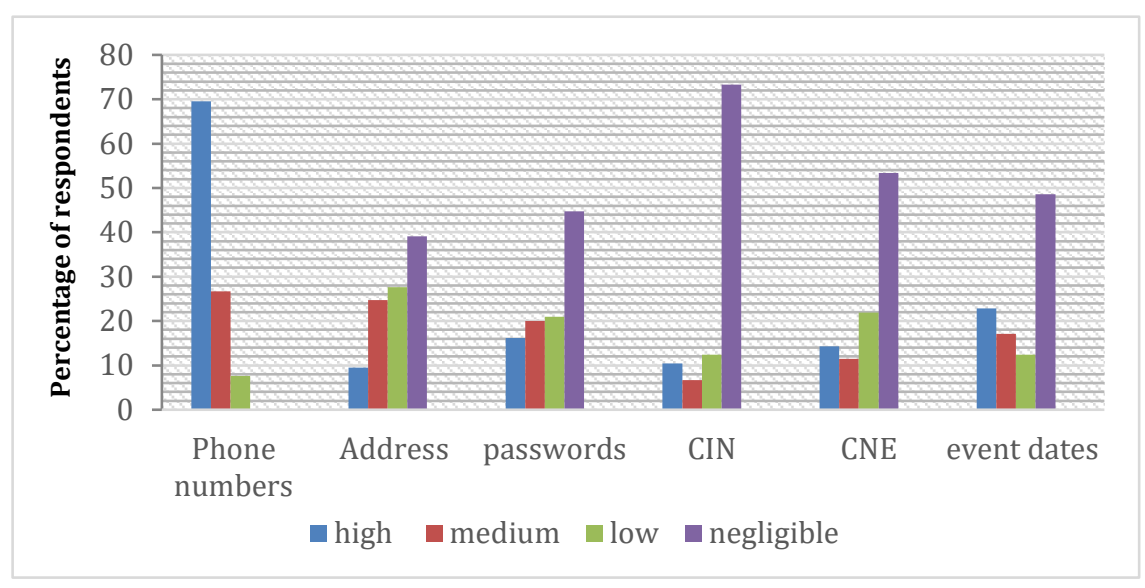

Fig. 4. Degree of reliance on digital tools in saving some personal information

According to the results obtained, Moroccan scientific students don't appear to be relying on digital tools for recording personal information with the exception of telephone numbers, the majority $(70 \%)$ of them rely on digital tools to record them.

This can be explained by the fact that the important function of smartphones is making phone calls because saving contacts is convenient. However, the Moroccan student does not seem to have developed such abilities one example being to save personal information such as the national identification number, student number and event dates in their digital tools. 


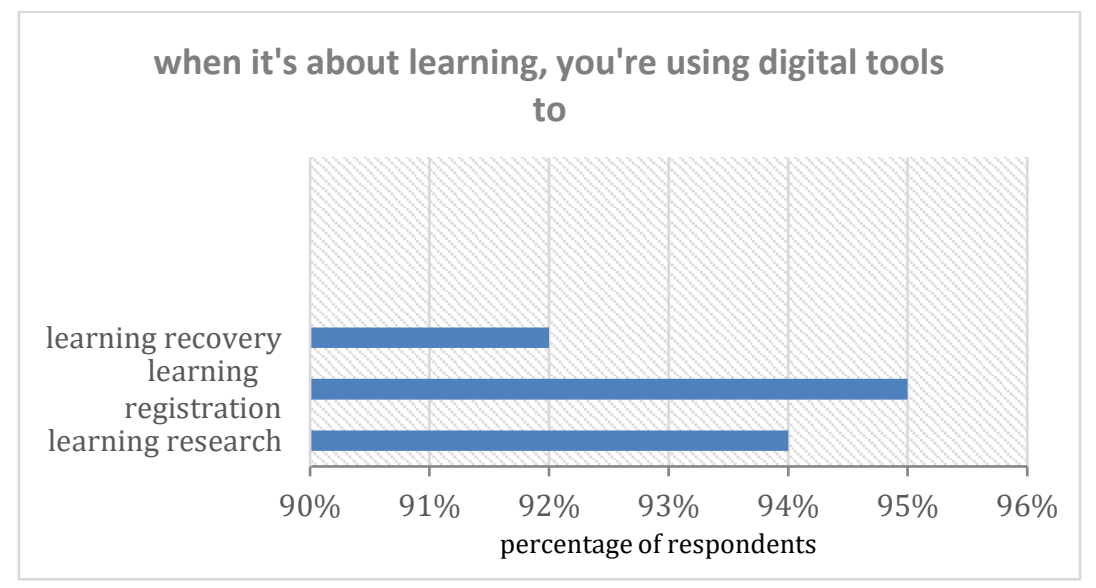

Fig. 5. Digital use of students in the field of learning

The histogram above shows that almost the majority of our students say they use digital tools in all learning activities, from the search for information to its registration.

Thus, our students rely on digital tools and the internet for their learning. This leads us to ask the following question; Is a massive use of the digital tools likely to weaken the process of memorization for students?

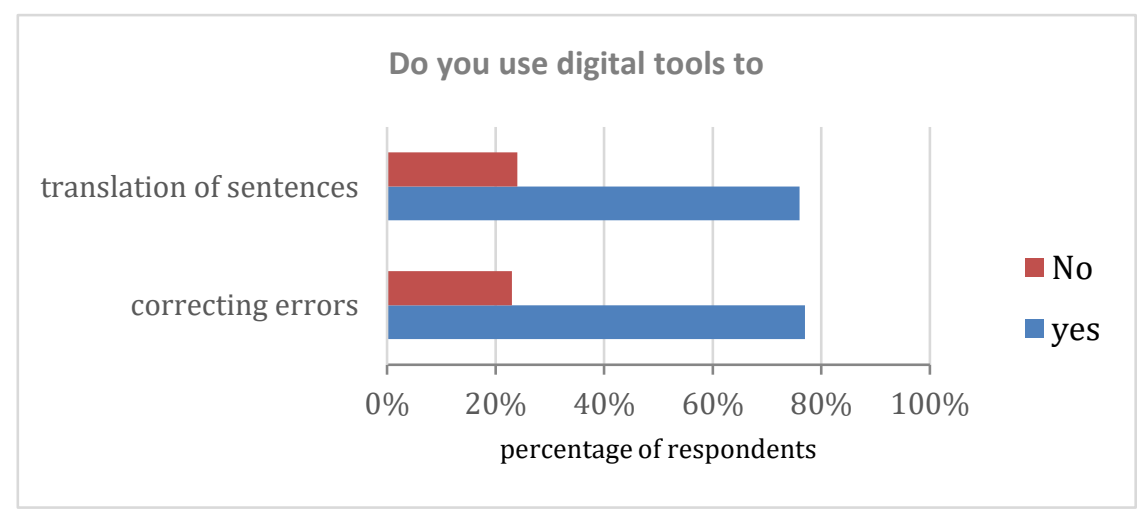

Fig. 6. The importance of Digital Tools in language proficiency

From the histogram above, it is quite clear that the majority of students in our sample, rely on digital tools to correct spelling errors and to translate sentences.

Mastering these two skills requires a strong memory that evolves through frequent practice. However, the internet or mobile applications that are for corrections or translation, facilitate the task and therefore they promote forgetfulness since it involves short-term memory and not long-term memory. Accordingly, if the student needs to correct or translate the same sentence again, chances are the result will be the same. 
So, the memorization process has changed, since the student memorizes the path of information and not the information itself.

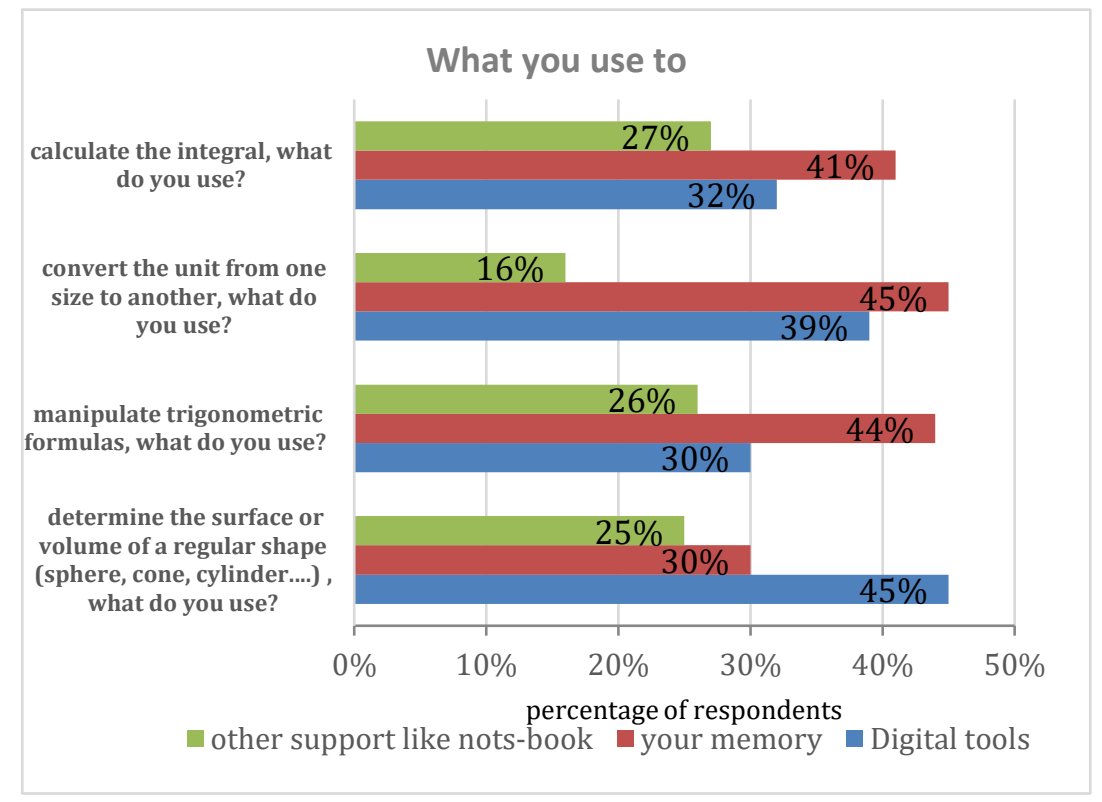

Fig. 7. Means used in the recovery of scientific knowledge

The result shows that on average $60 \%$ of students do not rely on their memories to recover scientific knowledge, but rather rely on other media as an external memory.

For the purpose of comparing digital tools with other media (paper documents, notebooks, etc.), the histogram above shows the priority of using digital tools as a direct alternative to information recovery.

The result also focuses on the evolution of the growth rate in the use of these digital tools compared to conventional procedures (paper documents, notebooks, etc.) and internal memory.

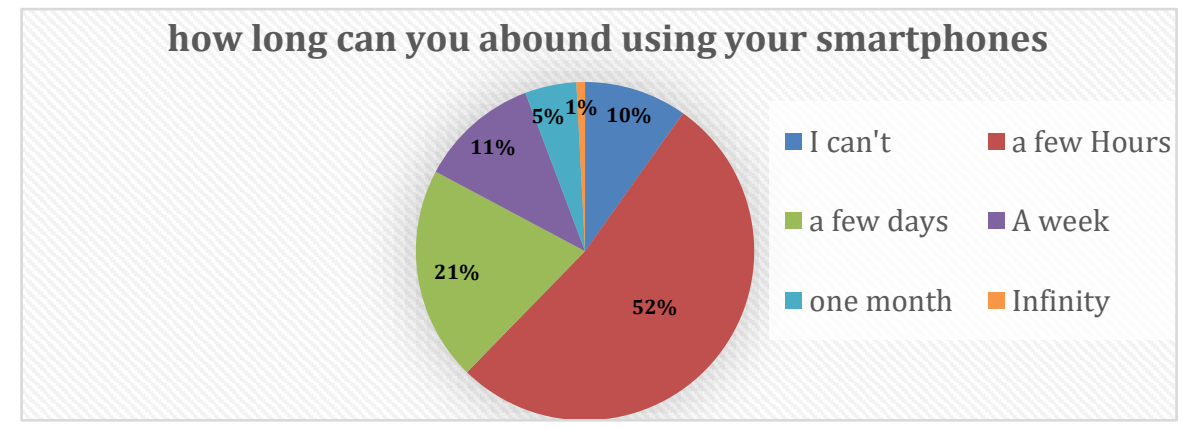

Fig. 8. Degree of dependence on smartphones 
Moroccan science students are addicted to smartphones, as only half of them can give up their uses for a few hours, and $10 \%$ say that they are unable to do so.

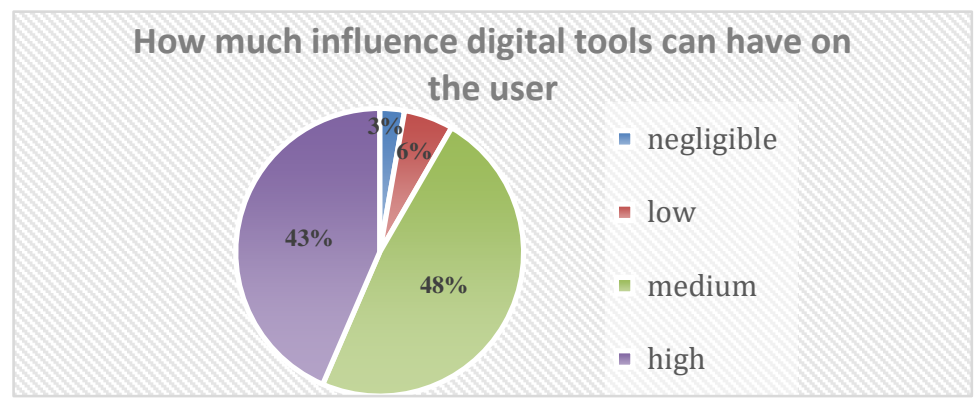

Fig. 9. Influence of digital tools on the user

The majority of students believe that digital tools have a medium or even strong impact on the user.

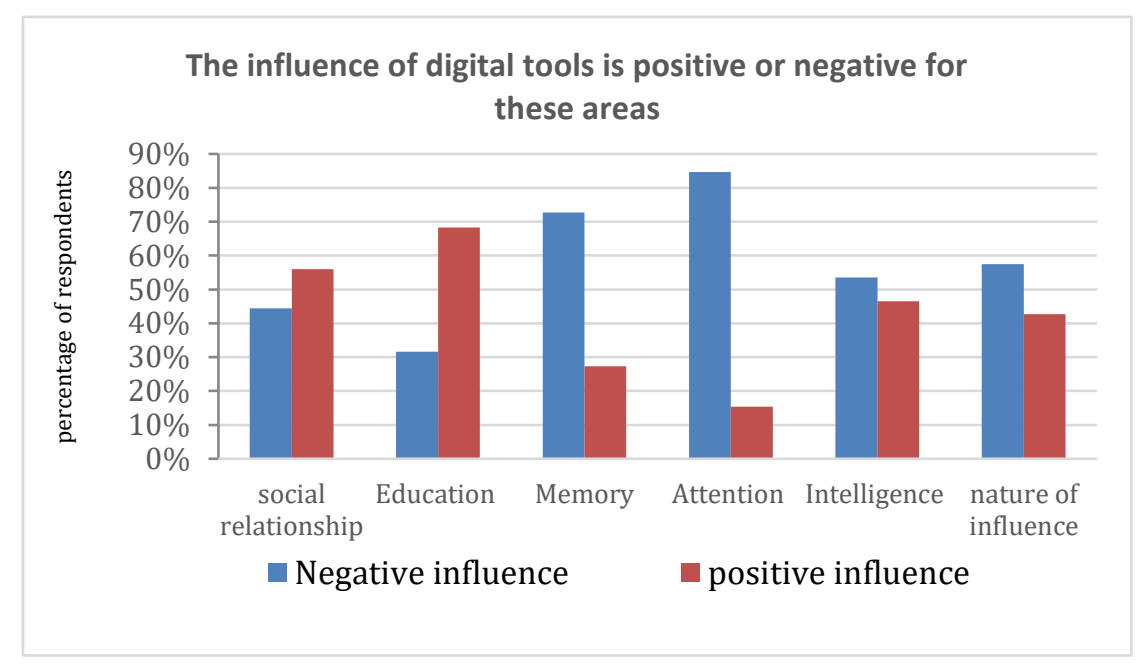

Fig. 10.Nature of digital tools influence

$43 \%$ of science students confirm that digital tools have a positive impact, while $57 \%$ say that the true nature of the influence is negative.

However, the majority believe that the negative influence mainly affects attention $(85 \%)$ and memory $(73 \%)$, but the positive influence affects education.

This result emphasizes misrepresentation in the Moroccan scientific student since he considers the influence as positive in the case of education. At the same time, he considers the influence as negative on memory and attention, without taking into consideration that these two parameters are the keys to effective learning.

The study informs that Moroccan scientific students use digital tools to search for an information, but not to record it in their memory. Therefore, they must seek the 
same information when needed, which gives them a feeling of inconvenience in their memory capacity.

The reason why they perceive these digital tools as a negative influence on the memory is; That the memorization process is closely related to the attentional abilities dedicated to an activity. Therefore, the continued availability of information leads to a lack of attention during a search and subsequently the memorization process is less effective.

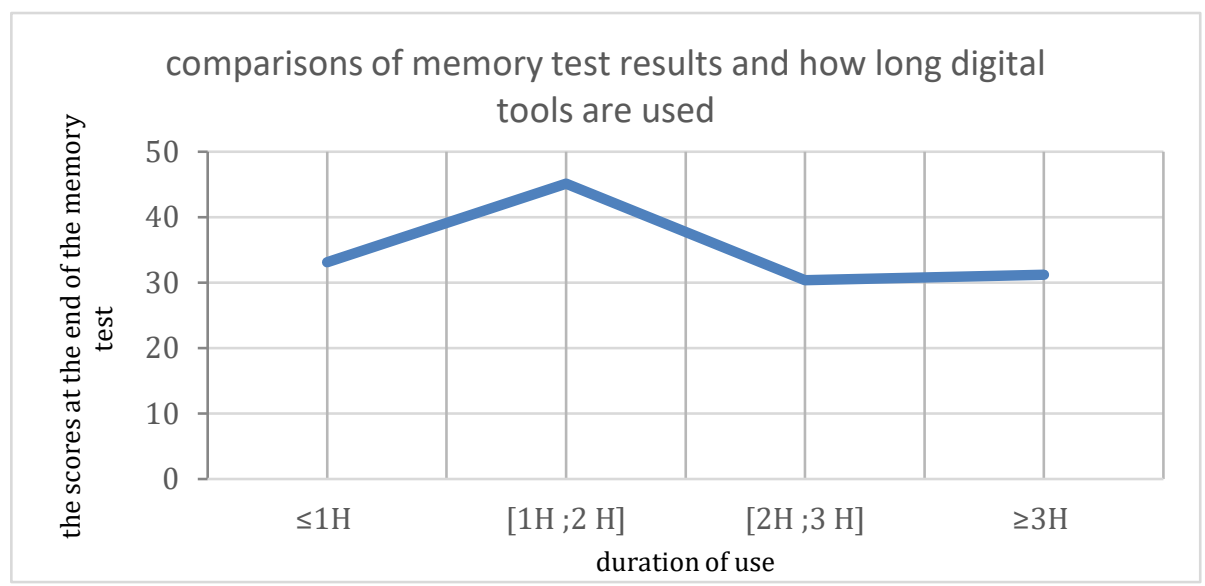

Fig. 11.The influence of digital tools on memory

Taking into account that the memory test is graded from 75 , the study shows that among students who took the memory test, only those who use digital tools for (1-2) hours a day, had an average score of $45 / 75$, but the other 3 classes (less than $1 \mathrm{~h}$, between $2 \mathrm{~h}$ and $3 \mathrm{~h}$ and more than $3 \mathrm{~h}$ ) had an average score of $31.5 / 75$, which is below average.

So, the use of digital tools for a duration between (1h-2h) seems beneficial for memory, but when use exceeds $2 \mathrm{~h}$ per day it then has a negative impact on memory. $\mathrm{Up}$ to $3 \mathrm{~h}$ and more, this negative influence remains stable. However, to the results show that those who rarely use digital tools don't benefit from the positive influence that they could have. 


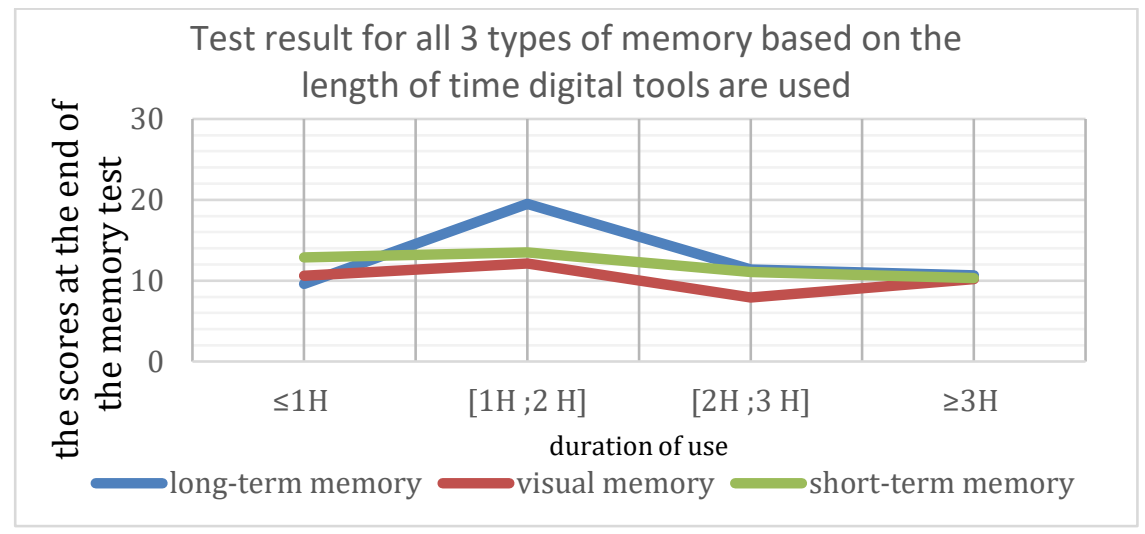

Fig. 12.Influence of digital tools on memories

On the one hand, the daily use of Digital Tools has no influence on Visual Memory (MV) and Short-Term Memory (MCT), but on the other hand their MCT is more effective than the MV when Recovering.

However, daily use of Digital Tools has a positive impact on long-term memory (MLT) when it is between $1 \mathrm{~h}$ and $2 \mathrm{~h}$, but this influence is negative when it is greater than $2 \mathrm{~h}$.

And indeed, the students who used Digital Tools for a duration between $1 \mathrm{~h}$ and $2 \mathrm{~h}$ had higher scores in the MLT test, but those who exceeded $2 \mathrm{~h}$ had lower scores.

In addition, the study indicated that the memorization process changes with the daily duration of using digital tools. But it should be noted that the gradual increase in duration is accompanied by a regression in memory quality because the memorization process involves MV more than MCT and MLT.

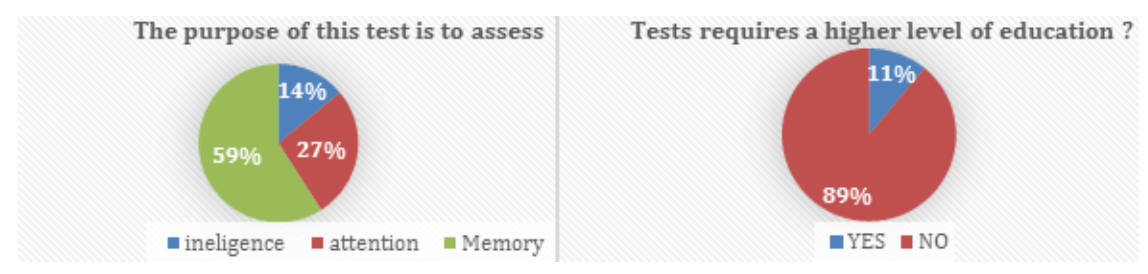

Fig. 13.The students' view on the memory test

According to the previous results, two-thirds of students who took the test believe that it targets the evaluation of their dissertations, while the majority of them consider it an easy test that doesn't require a high education level.

That highlights the results of the test, questionnaire, and consequently the entire study. 


\section{Conclusion}

First, the study confirms that there is a trend towards heavy use of digital tools with a clear dominance of smartphones over the laptops and the tablets.

Actually, almost half of Moroccan scientific students use their digital devices for $18.75 \%$ of their free time.

Second, Moroccan students mainly use digital tools in the areas of entertainment with the predominance of social networks and games, but only $34 \%$ of these uses are for educational purposes.

In addition, the study shows that there are no significant differences in the way digital tools are used when it comes to learning areas, since the majority of students use them first to search for information and then for its registration. Nevertheless, the results show that those digital tools can become increasingly important in the coming years, giving the increasing scope of their use, precisely as an external memory.

Finally, digital tools tend to be necessary for language proficiency, as 3/4 of Moroccan science students use them to translate sentences or to correct them.

Moroccan scientific students rely less on digital tools for recording personal information. However, they tend to rely on digital tools for learning, which negatively influences their memorization process, resulting in a low attentional capacity at the time of searching for an information.

So, the study shows that the availability of information through these digital tools contributes to a superficial processing of information. This in turn explains why the majority of students report that digital tools have a negative influence on memory and attention.

Finally, the study states that the use of digital tools has a direct influence on memorization as a learning process.

However, the nature of influence depends on the duration of use, as it seems positive when the use is between $1 \mathrm{H}$ and $2 \mathrm{H}$ (moderate use). Nevertheless, it seems negative when this duration of use exceeds $2 \mathrm{H}$.

While the learning process involves all 3 types of memory, the results of the study indicate that the use of digital tools mainly affects the MLT, but has no influence on MS and TCM.

From the analysis of the results, it is clear that the memorization process involves the different types of memory so it seems effective, since it keeps the natural sequence of intervention of the 3 types of memories named MS then MCT and finally the MCT when the duration of use is between one hour and 2 hours. Thus, when the duration of use exceeds 2 hours this process tends towards the use of a less efficient memory during recovery, named the MS.

So, the recommended amount of time $[1 \mathrm{H}-2 \mathrm{H}]$ per day seems disruptive to the memorization process.

In a few words, the use of digital tools for a moderate duration is beneficial for the memorization process, while mass use seems detrimental to the memorization process insofar as it neglects the MLT. Which constitutes the nucleus of human knowledge so technophobes do not benefit from the positive effect that moderate use of digital tools can have on the memorization process. 
Proving that the influence of digital tools on the memorization process was not positive or negative was not the main objective of our study, but rather the desire to push the owners of these digital tools to rethink their uses by adopting strategies of good use, in order to protect a characteristic component of humanity namely our ability to consciously memorize. However, we still have many facets to explore to interpret our results in more detail and apply them.

\section{$7 \quad$ References}

[1] Wang, X., \& Zhang, D. (2017). A study on the influence of computer corpus software on college students' English vocabulary learning. International Journal of Emerging Technologies in Learning (iJET), 12(08), 27-35. https://doi.org/10.3991/ijet.v12i08.7137

[2] Khouna, J., Ajana, L., Rhazal, A., \& El Mokri, A. (2019). Are Educational Games Engaging and Motivating Moroccan Students to Learn Physics? An Experimental Study. International Journal of Emerging Technologies in Learning, 14(16). https://doi.org/10.3991/ijet. $\underline{\mathrm{v} 15 \mathrm{i} 18.15455}$

[3] Kokkalia, G. K., \& Drigas, A. S. (2015). Working Memory and ADHD in Preschool Education. The Role of ICT'S as a Diagnostic and Intervention Tool: An Overview. International Journal of Emerging Technologies in Learning, 10(5). https://doi.org/10.3991/ijet. $\underline{v 10 i 5.4359}$

[4] Michaut, C., Roche, M., 2017. L'influence des usages numériques des étudiants sur la réussite universitaire. Rev. Int. Pédagogie L’enseignement Supér. 33. https://doi.org/10.40 $\underline{00 / \text { ripes. } 1171}$

[5] Boot, W.R., Kramer, A.F., Simons, D.J., Fabiani, M., Gratton, G., 2008. The effects of video game playing on attention, memory, and executive control. Acta Psychol. (Amst.) 129, 387-398. https://doi.org/10.1016/j.actpsy.2008.09.005

[6] Sparrow, B., Liu, J., Wegner, D.M., 2011. Google Effects on Memory: Cognitive Consequences of Having Information at Our Fingertips. Science 333, 776-778. https://doi.org/ $10.1126 /$ science. 1207745

[7] Michel VOISIN, L'enfant et les écrans: regard du pédiatre , Académie des Sciences et Lettres de Montpellier 6 juin 2016,139 , n.d. https://www.ac-sciences-lettres-montpellier.fr/ academie_edition/fichiers_conf/VOISIN-2016.pdf (accessed 26.7.20)

[8] Tulving, E. (1972). Organization of memory. Episodic and semantic memory.

[9] Roediger, H.L., Crowder, R.G., 1976. A serial position effect in recall of United States presidents. Bull. Psychon. Soc. 8, 275-278. https://doi.org/10.3758/BF03335138

[10] Baddeley, A., 2000. The episodic buffer: a new component of working memory? Trends Cogn. Sci. 4, 417-423. https://doi.org/10.1016/S1364-6613(00)01538-2

[11] Atkinson, R. C., \& Shiffrin, R. M. (1968). Human memory: A proposed system and its control processes. Psychology of learning and motivation, 2(4), 89-195. https://doi.org/10. 1016/s0079-7421(08)60422-3

[12] Courtois, S. (2017). L'influence de l'utilisation des cartes mentales sur la mémorisation des concepts de sciences.

[13] Baddeley, A. (1992). Working memory. Science, 255(5044), 556-559. https://doi.org/10. $\underline{1126 / \text { science. } 1736359}$

[14] Baddeley, A. D., \& Hitch, G. (1974). Working memory. In Psychology of learning and motivation (Vol. 8, pp. 47-89). Academic press. https://doi.org/10.1016/s0079-7421(08) $\underline{60452-1}$ 
[15] Cowan, N., 2008. Chapter 20 What are the differences between long-term, short-term, and working memory? in Progress in Brain Research. Elsevier, pp. 323-338. https://doi.org/ 10.1016/S0079-6123(07)00020-9

[16] Lieury, A., Van Acker, P., Clevede, M., \& Durand, P. (1992). Les facteurs de la réussite scolaire: raisonnement ou mémoire sémantique? 2ème année d'une étude longitudinale en cycle secondaire (5e). Psychologie et psychométrie, 13(1), 33-46.

[17] Kalafat, M., Hugonot-Diener, L., \& Poitrenaud, J. (2003). Standardisation et étalonnage français du "Mini Mental State" (MMS) version GRECO. Revue de neuropsychologie, 13(2), 209-236.

[18] Dalrymple-Alford, J. C., MacAskill, M. R., Nakas, C. T., Livingston, L., Graham, C., Crucian, G. P., ... \& Porter, R. J. (2010). The MoCA: well-suited screen for cognitive impairment in Parkinson disease. Neurology, 75(19), 1717-1725. https://doi.org/10.1212/wnl.0b $\underline{013 \mathrm{e} 3181 \mathrm{fc} 29 \mathrm{c} 9}$

[19] Brown, J., Pengas, G., Dawson, K., Brown, L. A., \& Clatworthy, P. (2009). Selfadministered cognitive screening test (TYM) for detection of Alzheimer's disease: cross sectional study. Bmj, 338, b2030. https://doi.org/10.1136/bmj.b2030

[20] Dubois, B. (2001). L’épreuve des cinq mots. Neurol Psychiatrie Gériatr, 1, 40-42.

[21] Rullier, L., Matharan, F., Barbeau, E. J., Mokri, H., Dartigues, J. F., Pérès, K., \& Amieva, H. (2014). The DMS 48: norms and diagnostic proprieties for Alzheimer's disease in elderly population from the AMI cohort study. Geriatrie et psychologie neuropsychiatrie du vieillissement, 12(3), 321-330. https://doi.org/10.1684/pnv.2014.0486

[22] Van der Linden, M., Coyette, F., Poitrenaud, J., Kalafat, M., Calicis, F., Wyns, C., \& Adam, S. (2004). II. L'épreuve de rappel libre/rappel indicé à 16 items (RL/RI-16).

\section{Authors}

Amine Hamzi is a PhD student at the laboratory of Computer and Interdisciplinary Physics (LIPI), ENS (Ecole Normale Supérieure), Sidi Mohammed Ben Abdellah University, Fez, Morocco. His research focused on the impact of using digital tools on the process of memorization.

Noureddine Echantoufi is a PhD student at the laboratory of Computer and Interdisciplinary Physics (LIPI), ENS (Ecole Normale Supérieure), Sidi Mohammed Ben Abdellah University, Fez, Morocco. His research focused on the students' conceptual understanding of the mechanics.

Jalal Khouna is a doctor in didactics of physical sciences $(\mathrm{PhD})$, he is member of laboratory of Computer and Interdisciplinary Physics (LIPI), ENS (Ecole Normale Supérieure), Sidi Mohammed Ben Abdellah University, Fez, Morocco. His research focused on educational games, competency-based approach and integration of ICT into teaching and learning.

Lotfi Ajana is professor at ENS (Ecole Normale Supérieure), sidi Mohamed Ben Abdellah university, Fez Morrocco. Founding member and permanent member of laboratory of Computer and Interdisciplinary Physics (LIPI). He does research in didactic science and TICE (Technologies of Information and Communication for Education).

Article submitted 2020-09-06. Resubmitted 2020-10-26. Final acceptance 2020-10-27. Final version published as submitted by the authors. 


\section{$9 \quad$ Appendices}

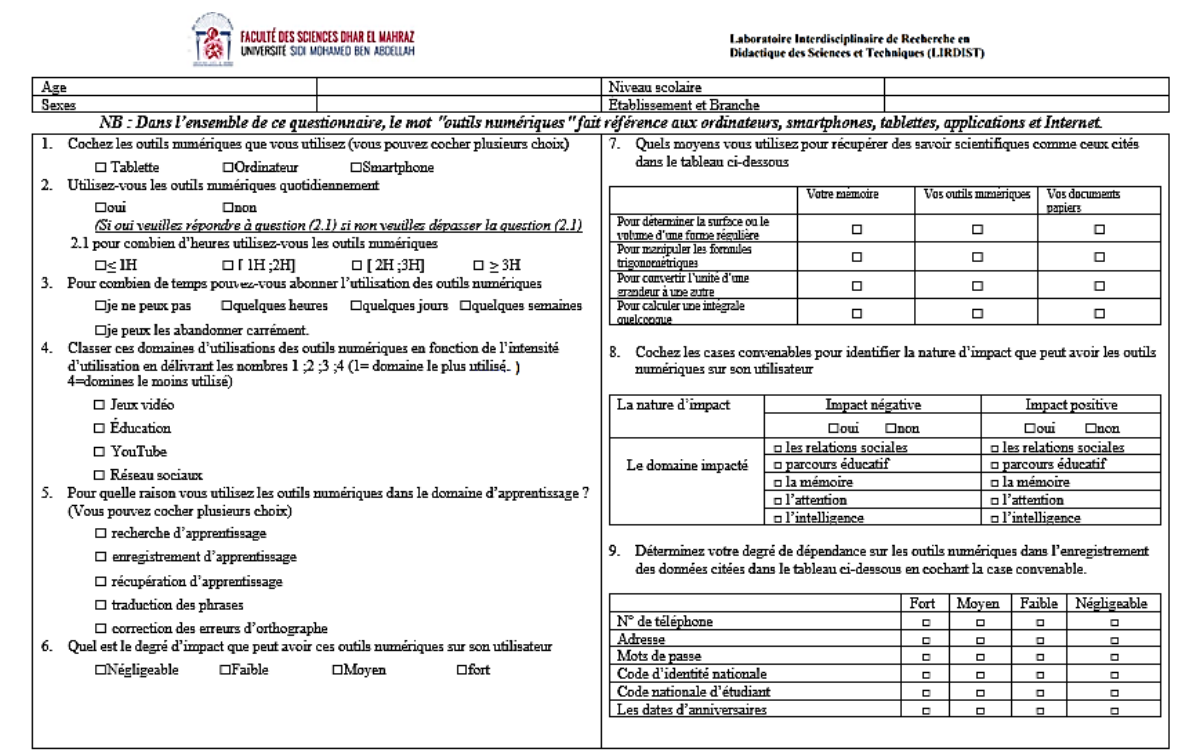

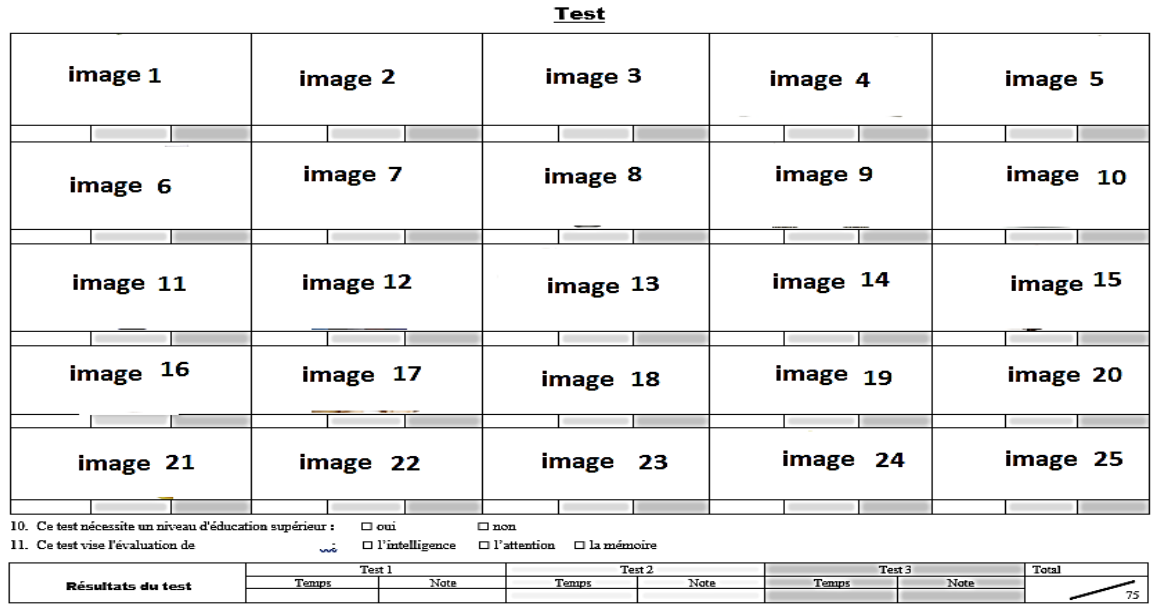

